\title{
TRAGEDIA DE LOS RECURSOS DE USO COMÚN Y ÉTICA AMBIENTAL INDIVIDUAL RESPONSABLE FRENTE AL CALENTAMIENTO GLOBAL
}

\author{
Juan Carlos Castilla ${ }^{1}$
}

Resumen: La tragedia de los recursos de uso común (sobreexplotación, contaminación) es una metáfora bien acuñada en la literatura. El aire es un recurso de uso común, sobre el que no existe propiedad privada. El problema del calentamiento global, derivado del exceso de gases de efecto invernadero $\left(\mathrm{CO}_{2}, \mathrm{NO}_{2}\right.$, metano), generados por actividades humanas y el excesivo consumismo, y que se almacenan en la alta atmósfera causando cambios climáticos, es hoy una tragedia. Vivimos una nueva Era llamada del Antropoceno. Las soluciones monocéntricas globales a esta tragedia, de arriba hacia abajo — por ejemplo, Protocolo de Kyoto, de 1997— han fracasado. El artículo destaca la necesidad urgente de comenzar a usar soluciones estratégicas policéntricas — de abajo hacia arriba—, acciones individuales y colectivas, en conjunto con las globales, para enfrentar la tragedia. Ello debe basarse en la instalación masiva de una nueva ética ambiental responsable, basada, por ejemplo, en el principio ético de responsabilidad individual de Kutz. Para ello se necesita poner en acción una ciencia ambiental posmoderna, creíble, con una democratización del conocimiento, y alfabetizar a la sociedad en forma simple y directa sobre la información dura del cambio climático en todas sus dimensiones: negativas, positivas y de nuevas oportunidades. Los medios de comunicación social masivos pueden ser la clave para lograr este objetivo.

Palabras clave: calentamiento global, recursos comunes, ética responsable, gobernanza, Antropoceno, acciones colectivas, ciencia postmoderna, educación, comunicaciones

\section{Tragedy of the common pool resources and environmental ethics individually liable to global warming}

\begin{abstract}
The tragedy of the commons (overexploitation, pollution) is a metaphor well anchored in the literature. The air is a common pool resource and private property does not exist. The global warming of the planet, caused by excess greenhouse gas emissions $\left(\mathrm{CO}_{2}, \mathrm{NO}_{2}\right.$, methane), generated by human activities and consuming society, which are stored in the high atmosphere causing climatic changes, is today a tragedy. We live in a new Era, that of the Antrophocene. Monocentric solutions to this tragedy: top-down — for instance the Kyoto Protocol of 1997— have failed. The article highlights the urgent need to implement polycentric solutions to face the tragedy: bottom-up, individual and collective actions in concurrence with topdown strategies. This needs to be based in the installation of a new environmental responsible ethic, for instance based in the individual responsible Kutz ethic principle. For this is needed to promote, as soon as possible, a postmodern environmental science, with credibility and a true democratization of knowledge. Moreover, there is a need for environmental alphabetization of our society based on hard knowledge about climatic changes and global warming, in all dimensions: negative, positive, new opportunities. The use of massive communication tools may be the key to achieve the goal.
\end{abstract}

Key words: global warming, common resources, responsible ethics, governing, Antropoceno, collective actions, postmodern science, education, communications

\section{Tragédia dos recursos de uso comum e ética ambiental individual responsável frente ao aquecimento global}

Resumo: A tragédia dos recursos de uso comum (superexploração, contaminação) é uma metáfora bem cunhada na literatura. $\mathrm{O}$ ar é um recurso de uso comum, sobre o qual não existe propriedade privada. O problema do aquecimento global derivado do excesso de gases de efeito estufa (CO2, NO2, metano), gerados por atividades humanas e o excessivo consumismo, que se armazenam na alta atmosfera causando mudanças climáticas, é hoje uma tragédia. Vivemos uma nova Era chamada de Antropoceno. As soluçôes monocêntricas globais a esta tragédia, de cima para baixo - por exemplo, Protocolo de Kyoto de 1997 - fracassaram. O artigo destaca a necessidade urgente de começar a usar soluçôes estratégicas policêntricas - de baixo para cima -, açóes individuais e coletivas, em conjunto com as globais, para enfrentar a tragédia. Isso tem que basear-se na instalaçáo massiva de uma nova ética ambiental responsável por exemplo, baseada no princípio ético de responsabilidade individual de Kutz. Para isso se necessita por em acçáo uma ciência ambiental pós-moderna, crível, com uma democratização do conhecimento, e alfabetizar a sociedade de forma simples e direta sobre a informação dura da mudança climática em todas suas dimensôes: negativas, positivas, novas oportunidades. Os meios de comunicaçáo social massivos podem ser a chave para lograr este objetivo.

Palavras-chave: aquecimento global, recursos comuns, ética responsável, governança, Antropoceno, açóes coletivas, ciência pós-moderna, educação, comunicaçóes

\footnotetext{
${ }^{1}$ Departamento de Ecología, Centro de Cambio Global-PUC y Núcleo Milenio de Biodiversidad Marina, Facultad de Ciencias Biológicas, Pontificia Universidad Católica de Chile, Chile

Correspondencia: jcastilla@bio.puc.cl
} 


\section{Introducción}

La tragedia de los recursos de uso común es una metáfora usada por Garrett Hardin(1) para describir una situación en la que varios pastores incrementan sus cabezas de ganados dentro de un pastizal (recurso común), al que todos tienen acceso irrestricto y en el cual el alimento (pasto) es finito. Esto eventualmente lleva al agotamiento y sobreexplotación del recurso finito, la consecuente pérdida del ganado y a una tragedia para todos los usuarios. La metáfora se basa en una simplificación de las relaciones de estructuras sociales y sus consecuencias respecto del uso de recursos finitos de uso común, y dio origen a un amplio debate. El dilema que plantea Hardin es básicamente uno de comportamiento social racional, en que están en juego la libertad, la responsabilidad y la gobernanza. Para solucionar la "tragedia del agotamiento de los recursos de uso común", el autor planeta básicamente dos soluciones: (a) la privatización, (b) la estatización de los recursos. El trabajo ha sido ampliamente citado en la literatura y existen numerosas referencias que muestran otras soluciones de gobernanza, adicionales a las sugeridas por Hardin, como salidas posibles a la tragedia(2-6).

El aire, el agua y los recursos marinos son recursos típicos de los habitantes de la Tierra, que todos compartimos y de los cuales dependemos, y en que no existen (o no deberían existir) derechos de propiedad individual. Por eso son denominados "recursos de uso común" ("common-pool resources") y deben ser racionalmente gobernados. No hacerlo — contaminarlos, dañarlos, sobreexplotarlos o destruirlos - no solo va en detrimento de sus usos por las generaciones presentes, sino que también por las futuras.

\section{El efecto invernadero y el calentamiento global}

La tasa de emisión acelerada al aire (atmósfera) por los seres humanos — post revolución industrial y en especial post segunda guerra mundial (últimos 150 años) - de gases como el anhídrido carbónico (un gas incoloro e inodoro), metano y óxidos de nitrógeno, entre otros, ha producido ya un cambio físico químico en la alta atmósfera, conocido como el "efecto invernadero". Este efecto ha redundado en cambios del clima ${ }^{2}$ en el planeta. Una de las consecuencias de ello es el denominado "calentamiento global", sobre el cual se han investigado sus orígenes e impactos pasados y actuales. Adicionalmente, los modelos nos permiten proyectar estos impactos a futuro, tanto para los ecosistemas naturales, la economía, como para los sistemas socioecológicos(7-9).

Es necesario mencionar que efectivamente existe una posición, notoriamente minoritaria, que duda de que el calentamiento global tenga sus causas en actividades humanas (como elemento principal) y señala como causales a fenómenos naturales y ciclos de la Tierra, o del sistema en que vivimos: ciclos solares, influencia de rayos cósmicos sobre la Tierra y ciclos de la misma Tierra. Según estos escépticos(10), el planeta ya habría pasado por situaciones de enfriamientos y calentamientos globales similares a las actuales, y lo que ocurre hoy sería solo parte de un ciclo natural. Estas posiciones escépticas sufren de fallas y, por ejemplo, no son capaces de explicar las muy aceleradas, nunca experimentadas antes, tasas de incremento de la concentración de $\mathrm{CO}_{2}$ equivalente en la alta atmósfera.

Por el contrario, hoy existe un consenso científico amplio sobre la influencia directa de las acciones del ser humano, ligadas al consumismo y a políticas económicas predominantes, como detonantes de cambios climáticos, por ejemplo, el calentamiento global. Así, frente a este problema, del cual todos somos parte de la causa y también de la solución, mi primer objetivo es enfrentar al lector con esta afirmación: "Frente a problemas globales ambientales, como el cambio climático, que nos afectan a todos, mi contribución individual a las soluciones es tan infima que no vale la pena hacer un esfuerzo: problemas de nivel planetario terrestre deben ser solucionados globalmente". Mi segundo objetivo es analizar las distintas posiciones y confrontarlas en un marco de responsabilidad ética ambiental individual.

Sobre la base de mi experiencia con audiencias en que he planteado esta afirmación, relacionada con el calentamiento global (o, en general, con proble-

${ }^{2}$ Definido como los promedios de variables del tiempo atmosférico sobre datos de largo plazo, generalmente sobre 60-70 ańos..., que es diferente del tiempo atmosférico presente o de la próxima semana. 
mas derivados del uso de recursos comunes, como el aire, el agua o los recursos marinos), me atrevo a pronosticar que: (a) un porcentaje importante de los lectores estará de acuerdo con la afirmación y basarán la respuesta en sus conocimientos generales, que respaldan que el cambio climático y el calentamiento global son fenómenos de nivel planetario, gatillados por acciones y conductas humanas, como el consumismo, pero solo solucionables globalmente. (b) Posiblemente otro grupo, menor, responderá negativamente: no, esa no es mi posición, en efecto yo soy parte del problema del calentamiento global, tengo estándares éticos ambientales individuales y contribuyo, tanto como puedo, a solucionarlo. (c) Quizás otro grupo, aún menor, se declarará imposibilitado de dar una respuesta, principalmente por falta de conocimiento en la comprensión cabal de los fenómenos, o también porque duda de que estos sean ciertos. Serán los poco informados, incrédulos o escépticos, que sí existen.

\section{Algunas de las preguntas clave}

¿Existe una conexión entre la ética individual ambiental y las soluciones planetarias a los grandes problemas ambientales, como el cambio climático? ¿Qué es un estándar individual ético ambiental? ¿Dónde comienza y dónde termina el compromiso ético ambiental individual responsable, en relación con un problema ambiental global como el cambio climático? ¿Es éticamente aceptable pensar que, estando yo en conocimiento de las causas y efectos del cambio climático, me incline solo por esperar que los líderes u organizaciones mundiales lo solucionen? ¿Dónde esta la belleza de declararse abiertamente ignorante o dudar de este cambio climático y además respecto de lo que puede significar mi responsabilidad ética individual en contribuir a la solución del problema? Por otra parte, ¿cuál es la responsabilidad de aquellos que saben más sobre las causas científicas y consecuencias del cambio climático y no las comunican a la sociedad en forma simple y directa?

\section{El problema de los recursos de uso común y la ética responsable individual}

En el dilema de Hardin existe un solo un tipo de conducta humana: los pastores actúan en forma individual y motivados solo por su interés perso- nal; además no se comunican entre sí respecto del recurso común limitado o, si lo hacen, el resultado es el de no cooperación, prevaleciendo una actitud egoísta, que refleja una de las soluciones al dilema del prisionero, de Albert W. Tucker. En este modelo (teoría de juego) se muestra como dos personas pueden no cooperar incluso si en ello se juega el interés de ambas. Si la "tragedia del uso de recursos comunes" se lee en clave ética, la conclusión es que cada pastor que usa los recursos comunes solo privilegia sus derechos individuales, los inclina solo en su favor y, a través de ello, eventualmente, perjudica a los demás y a final se perjudica a sí mismo. Del ejemplo se podría colegir que la conducta de esos pastores se enmarca en una ética de corte "utilitarista no informada", en que cada pastor tiene como objetivo único maximizar su bienestar individual, pero no tiene información sobre el conjunto de los usuarios o sobre lo limitante de los recursos. En el mundo que colorea Hardin, todos los pastores tienen los mismos derechos individuales al uso de los recursos, existe libertad para su uso y no existe comunicación entre ellos: no hay espacio para la acción colectiva. Si los recursos de uso común son finitos, entonces ocurrirá una "trampa social", que llevará a su sobreexplotación o daño, con un detrimento final para todos los participantes. Este es uno de los escenarios éticos de la Tragedia de los Comunes de Hardin. La solución que propone Hardin es coercitiva, al considerar solo la privatización o la estatización como posibles salidas. El trabajo de Hardin ha sido criticado, entre otras razones por excluir otros arreglos institucionales de derecho (legales) o de hecho (tradicionales) $(11,12)$.

El caldo de cultivo en el que se engendraría la tragedia de los comunes de Hardin es un mundo sin comunicación, extremadamente egoísta y con falta de cooperación. Efectivamente, existe una casuística extensa en el mundo en la que esto ha ocurrido y continúa ocurriendo, y por ello la tragedia de los recursos de uso común no es un mito, sino parte de una realidad. Sin embargo, no es menos cierto que en el mundo real del uso y cuidado de los recursos de uso común existen también aproximaciones de colaboración, comunitarias y de acciones colectivas entre los usuarios(13). Desde el punto de vista ético formal, una de las alternativas, contrastante con la ética individual y la "utilitarista no informada", es el 
ejercicio de una ética individual de "preferencia utilitarista"(14), en la cual el individuo se comporta balanceando sus preferencias propias y las de aquellos que serán afectados con su accionar. Este tipo de ética no es alcanzable en una sociedad sin comunicación entre los actores, extremadamente competitiva y egoísta, y en la que ni existe ni se acumula ni se comunica la experiencia y el conocimiento.

\section{La Era del Antropoceno}

Vivimos la Era del Antropoceno(15) y la solución al incremento persistente en la concentración de gases de efecto invernadero en la alta atmósfera y el calentamiento global es altamente dependiente de los mecanismos de gobernanza planetarios, de aquellos impuestos por los países, de los acordados por las comunidades y de las conductas de los individuos y los colectivos. En efecto, el aire es un recurso común y respecto de él existen frondosas legislaciones en los países para el control de contaminantes aéreos en la baja atmósfera ( $c a$. el primer kilómetro sobre la Tierra), principalmente por sus efectos en la salud humana. Sin embargo, esto no es así (o escasamente en algunos países ambientalmente más avanzados) en relación con la calidad del aire en la alta atmósfera (más allá del primer kilómetro y hasta los 10 kilómetros de altura), donde terminan acumulándose los gases de efecto invernadero.

El Protocolo de Kyoto de las Naciones Unidas, en el Marco de la Convención sobre Cambio Climático de 1997, entró en vigencia en 2005 y en 2008 ya había sido ratificado por 182 países. No obstante, este protocolo multinacional ha fracasado como una herramienta de gobernanza planetaria para detener o estabilizar el aumento en la concentración de los gases de efecto invernadero(16). Entonces, ¿tiene algún sentido práctico contribuir individualmente frente a un problema ambiental de carácter planetario? Por ejemplo, si un chileno en promedio emite al año cinco toneladas de anhídrido carbónico equivalente, ¿tiene algún sentido que reduzca su emisión de $\mathrm{CO}_{2}$ cuando la emisión global anual es de miles de millones y millones de toneladas? ¿Cuál es la dimensión de lo que llamamos una ética ambiental individual responsable? ¿Cuál es la connotación y significación de una ética individual ambiental?

\section{Problemas que es posible resolver mediante la integración de la ética ambiental individual responsable volcada hacia acciones colectivas}

Una aproximación ética a los problemas relacionales humanos con los recursos de uso común, consiste en enfocarse en los individuos y en los colectivos: por ejemplo, en los individuos de una comunidad, de un curso en un colegio o de una familia. Si nos centramos en el individuo y sus relaciones con los otros individuos de su entorno, aparece como fundamental la relación social de "responsabilidad" entre ellos, relación que nos distingue y nos diferencia de las relaciones de otros animales entre sí. Una persona al interior de una comunidad puede ser considerada responsable de un acto determinado, no solo por las consecuencias de lo que la persona hace en forma deliberada, sino que también por las consecuencias de aquello que deja de hacer.

Una formulación de la conducta ética individual responsable es el principio ético de complicidad de Kutz: "yo soy responsable de los que otros hacen cuando intencionalmente participo en el hecho erróneo que ellos hacen o en el problema que ellos causan" (17). Esta responsabilidad individual es independiente de la diferencia que signifique mi propia acción individual, por insignificante que ella sea: aun así, yo soy responsable por el conjunto(14). En último término, una ética individual responsable significa que los individuos piensan en sí mismos como inclusivamente responsables por daños causados colectivamente, aunque no lo hayan hecho en forma deliberada(17).

Otra arista de la ética individual responsable es aquella relacionada con la información y conocimiento con que cuenta o no cuenta una persona. Si la persona no cuenta con el conocimiento necesario para tomar una decisión, obviamente no es responsable por su conducta de acción o inacción. Pero, por otro lado, si cuenta con el conocimiento, no es solo responsable individualmente sino que solidariamente respecto del grupo o la comunidad. Esto es central en el tema que aborda este ensayo, pues significa que la responsabilidad ética individual de "una persona con conocimiento" no termina donde termina físicamente la persona, sino que su responsabilidad es grupal y solidaria, y finaliza al menos en los contornos de su grupo, comunidad o colectivo. 
En la base de estos principios éticos de responsabilidad individual está no solo la respuesta a la afirmación con que se abrió este ensayo, sino que a las más específicas de la sección anterior. Entonces, algunas de las respuestas podrían ser las siguientes: (a) Sí, tiene sentido de responsabilidad ética que yo haga esfuerzos y contribuciones individuales para detener o mitigar el problema de la acumulación de gases de efecto invernadero en la alta atmósfera, a pesar de que se trata de un problema de carácter planetario y global. (b) Sí, efectivamente, la dimensión de lo que se llama una ética ambiental individual responsable, en relación con la acumulación de gases de efecto invernadero, depende de que me informe, entienda el fenómeno, sus causas y consecuencias, y realice acciones mitigadoras individuales, y no solo espere que otros (globalmente) solucionen el problema por mí. (c) Sí, realmente, existe una connotación ambiental éticamente responsable en lo individual: si yo conozco las causas y los impactos de la acumulación de los gases de efecto invernadero, ciertamente mi responsabilidad ética no es solo individual, sino también solidaria-grupal-colectiva, cuyo núcleo base es, primero, mi familia y mis otros contornos sociales: escuela, comunidad, municipalidad, ciudad.

A partir de lo anterior, es posible iniciar acciones de responsabilidad ética ambiental individual que allanen el camino hacia acciones colectivas. Los dilemas sociales de las acciones colectivas son ampliamente conocidos e incluyen conflictos entre opciones racionales tomadas por los individuos, versus los resultados (óptimos o subóptimos) para el grupo; los costos individuales de contribuir a una acción determinada están concentrados en el individuo, mientras que los beneficios son difusos(18). El caso del cambio climático global y el calentamiento del planeta es paradigmático en ello. Sin embargo, como lo ha expresado la Premio Nobel en Ciencias Económicas 2009, Elinor Ostrom, en relación con el calentamiento global en el planeta: "Es improbable que políticas individuales adoptadas solo a escala global generen suficiente confianza entre los ciudadanos y las compañías (negocios), de modo que se produzcan acciones colectivas de una forma integrada y transparente, y que efectivamente signifiquen una reducción del calentamiento global" $(19)^{3}$.

${ }^{3}$ Traducción libre.
Ciertamente, el Protocolo de Kyoto y otros acuerdos multinacionales, como los de Río de Janeiro (1992), Johannesburgo (2002) y Río de Janeiro +20 (2012), no solo han sido incapaces de reducir las tasas de emisiones de gases de efecto invernadero en los pasados 20 años, sino que no han insuflado "confianza" en los individuos, tanto de los países desarrollados como de aquellos en vías de desarrollo. El gran desafío para la resolución de problemas ambientales colectivos es que son eso: problemas colectivos que solo pueden ser resueltos tomando en consideración diferentes aproximaciones de acción, denominadas como "soluciones policéntricas". Asumir que este problema, tanto desde el punto de vista de las emisiones, mitigaciones, como de adaptaciones al cambio climático, será resuelto solo en forma unicéntrica/mococéntrica por los gobiernos o instituciones supranacionales, es un error grave. Existe teoría y experiencias en la solución de problemas asociados a procesos de nivel individual y comunitario-colectivo y de aprendizaje intergeneracional (sin duda de menor envergadura que el del calentamiento global), sobre la base del uso de aproximaciones policéntricas, que incluyen acciones de gobernanza de alto nivel y colectivas, con la participación de los ciudadanos(3).

Frente a los fracasos de las aproximaciones unicéntricas de gobernanza multilateral (Kyoto y otras) al problema del calentamiento global y otros cambios climáticos, hoy llegó el momento de ampliar la matriz de esfuerzos y de comenzar, adicional y paralelamente, a implementar estrategias de solución de tipo policéntricas, con alta participación de los individuos y de los colectivos, con énfasis en la responsabilidad ética ambiental personal. Esto no ocurrirá en el corto plazo, pero las soluciones a los problemas derivados del cambio climático son de largo plazo y deberíamos estar comprometiendo, con más decisión y fuerza, a las futuras generaciones en esa dirección. Para nosotros, los adultos, aún es posible contribuir en la solución a esta tragedia, sobre todo en aspectos de adaptación al cambio, pero en forma limitada. Las conductas éticas ambientales individuales responsables, como la discutida en este ensayo, no se modifican en la sociedad de la noche a la mañana. En este sentido, los científicos y los comunicadores tienen una alta responsabilidad. Los primeros debemos ser capaces no solo de investigar en el 
tema, sino de trasmitir los conocimientos en forma simple $(20,21)$; los segundos, de comunicarlos en forma responsable(22).

La arena bioética ambiental y los desafíos de la ciencia posmoderna

Los mayores desafíos de las ciencias posmodernas(23), en particular en temas ambientales, son la credibilidad y la democratización. La esencia de la ciencia es la controversia; así, de ella no se pueden esperar diagnósticos y recetas únicas e inmutables. Especialmente en la arena ambiental, las organizaciones multinacionales, gobiernos, agencias regulatorias, negocios, grupos de interés y el público, dependen de la investigación científica y de los avances tecnológicos para el diseño de políticas de gobernanza, apoyo de sus demandas, toma de acciones y, eventualmente, modificación de conductas en pos de emisiones, mitigaciones o adaptaciones. Los debates y controversias sobre el calentamiento global, cambio climático post revolución industrial y los riesgos en salud o en desarrollo económico para las generaciones actuales o las venideras, son evidentes y continuarán en el diario vivir. No obstante, a lo que se debe propender con más fuerza en la arena de los cambios de carácter global en el planeta es a una mayor democratización del conocimiento científico. Cada persona debe tener acceso a la información científica que necesita para conformarse una idea lo más cabal posible sobre las causas e impactos presentes y futuros. Sin ello es muy difícil aspirar a inculcar actitudes ambientales individuales éticamente responsables, que alienten e inspiren modificaciones conductuales en torno a emisiones, mitigaciones o adaptaciones frente al calentamiento global.

Uno de los elementos esenciales como motor de cambio de conducta es que, por ejemplo, cada persona tenga acceso fácil y expedito a la cantidad de $\mathrm{CO}_{2}$ equivalente o gases de efecto invernadero que individualmente emite a la atmósfera por año. Con ello la persona puede no solo cuantificar su aporte en emanaciones, sino que se puede fijar objetivos de reducción. En Chile, recientemente el Ministerio de Medio Ambiente ha puesto en línea una calculadora de emisiones (personales o familiares), de gases de efecto invernadero: http:/ www.mma.gob.cl/quieromejorarmihuella/.
La esperanza en el mundo de las comunicaciones y en una ética ambiental responsable individual

La gran esperanza para democratizar el conocimiento científico y actuar más proactivamente frente a cambios planetarios (emisiones, mitigaciones, adaptaciones) y, eventualmente, en la implementación de estrategias policéntricas, es que actualmente contamos con plataformas de comunicación rápida y accesible para todos, como nunca antes en la historia de la humanidad. Hoy es muchísimo más fácil, rápido y eficiente llegar con conocimientos a los individuos sobre la base de información electrónica. El papel ya perdió su valor comunicativo acelerado. Frente a un problema planetario grave y urgente, como el calentamiento global, contar con estos medios es una bendición tecnológica. Sin embargo, para sacar real provecho de ello las instituciones multinacionales, regionales y los países deben reconocer y asumir la urgente necesidad de iniciar acciones mitigadoras y adaptativas policéntricas - y no lo han hecho. Además de llegar con la información adecuada a los ciudadanos, debemos insuflarles confianza y procurar cambios éticos individuales: nosotros somos parte del problema y parte de la solución. Alcanzar estos logros, principalmente entre los niños o a través de acciones colectivas, es de extrema urgencia y es tarea de los maestros en nuestras escuelas. Actualmente esto no esta ocurriendo en relación con el uso del recurso común aire-atmósfera. Por lo tanto, la metáfora de Hardin para describir la situación en que los usuarios tienen acceso irrestricto a un recurso común, sin cooperación, que eventualmente conduce a dañarlo e inexorablemente a tragedias para los usuarios, es lo que estamos viviendo hoy con el cambio climático y necesitamos cambiarlo. La aproximación ética individual responsable a este problema planetario es solo una más de las herramientas para su abordaje futuro. Nuestro comportamiento respecto de la emisión de gases de efecto invernadero a la atmósfera debe cambiar $y$, para ello, los pilares fundamentales de nuestras relaciones sociales - libertad y responsabilidaddeben estar en el corazón una ciencia más creíble y democrática, y de una gobernanza ambiental más informada y cercana a la gente. 


\section{Agradecimientos}

Agradezco muy sinceramente las revisiones, co- mentarios y sugerencias de mis colegas y amigos Andrés Marín, Omar Defeo, Stefan Gelcich y Xavier Basurto.

\section{Referencias}

1. Hardin G. The Tragedy of the Commons. Science 1968; 162: 1243-1248.

2. Ostrom E, Burger J, Field CB, Norgaard RB, Policansky D. Revisiting the Commons: Local lessons, global challenges. Science 1999; 284: 278-282.

3. Dietz T, Ostrom E, Stern P. The struggle to govern the commons. Science 2003; 302: 1907-1912.

4. Ostrom E. A Diagnostic approach for going beyond panaceas. Proceedings of the National Academy of Sciences 2007; 104: 15181-15187.

5. Radkau J. Nature and power. A global history of the environment. N. York: Cambridge University Press; 2008.

6. Castilla JC. Un ensayo sobre ecosistemas, servicios, biodiversidad y bienestar humano, en el ámbito marino y aproximaciones hacia valorizaciones económicas. In: Figueroa E, (ed.) Biodiversidad Marina: Valorización, usos y perspectivas. Santiago de Chile: Editorial Universitaria; 2005: 571-581.

7. National Research Council. Atmosphere-biosphere interactions: Toward a better understanding of the ecological consequences of fossil fuel combustion. Washington, DC: National Academy Press; 1981.

8. American Association for the Advancement of Science. AAAS board statement on climate change. Washington, DC; 2006. Disponible en: http://www.aaas.org/news/press_room/climate_change

9. Intergovernmental Panel on Climate Change (IPCC). Climate Change 2007. Fourth Assessment Report: Climate Change 2007; 2007.

10. Lomborg B. El ecologista escéptico. Madrid: Espasa-Calpe; 2005.

11. McCay BJ. Achenson JM. The Question of the Commons. The Culture and Ecology of Communal Resources. Tucson: University of Arizona Press; 1987.

12. Ostrom E. Governing the commons: The evolution of institutions for collective action. N. York: Cambridge University Press; 1990.

13. Castilla JC, Manríquez P, Alvarado J, Rosson A, Pino C, Espoz C, et al. Artisanal "Caletas" as units of production and co-managers of benthic invertebrates in Chile. Canadian Special Publiaction of Fisheries and Aquatic Sciences 1998; 125: 407-414.

14. Singer P. Practical Ethics. Cambridge: Cambridge University Press; 2011.

15. Crutzen PJ. Geology of Mankind: the Anthropocene. Nature 2002; 415: 423.

16. Matthews HD, Caldeira K. Stabilizing climate requires near zero emissions. Geophysical Research Letters 2008; $35: 1-5$.

17. Kutz C. Complicity: Ethics and law for a collective age. N. York: Cambridge University Press; 2000.

18. Olson M. The logic of collective action: Public goods and the theory of groups. Cambridge, MA: Harvard University Press; 1965.

19. Ostrom E. A polycentric approach for coping with climate change. World Bank. Research working paper $\mathrm{N}^{\circ} 5095 ; 2009$.

20. Hassol SJ. Improving how scientists communicate about climate change. American Geophysical Union 2009; 89: 106107.

21. Castilla JC. Cambio climático global y educación: Alfabetización, socialización, sensibilización y urgencia. In: Comisión Nacional de Medio Ambiente (eds). Balance y perspectivas de la educación ambiental en Chile e Iberoamérica. Santiago de Chile; 2010: 175-183.

22. Center for Research on Environmental Decisions. The psychology of climate change communications: A guide for scientists, journalists, educators, political aides, and interested public. New York; 2009. Disponible en: http://cred.columbia.edu/ guide

23. Eckersley R. Postmodern Science: The decline or liberation of science? In: Stocklmayer S, Gore M, Bryant C. eds. Science communication in theory and practice. Dordrecht: Kluwer; 2001: 83-94.

Recibido: 2 de octubre de 2013

Aceptado: 29 de octubre de 2013 